\title{
COMPREENSÃO DA FUNÇÃO SOCIAL DA PROPRIEDADE NO BRASIL COLONIAL: REPENSANDO A EVOLUÇÃO DAS IDEIAS JURÍDICAS A PARTIR DE OAKESHOTT
}

\author{
UNDERSTANDING THE SOCIAL FUNCTION OF PROPERTY IN COLONIAL \\ BRAZIL: RETHINKING THE EVOLUTION OF LEGAL IDEAS \\ WITH OAKESHOT
}

\author{
Venceslau Tavares Costa Filho* \\ Pedro de Oliveira Alves ${ }^{* *}$
}

\begin{abstract}
Resumo: A presente pesquisa objetiva verificar a hipótese de exigências prévias estatais acerca do cumprimento de algum tipo de função social da propriedade imóvel durante os primórdios do Brasil Colonial. Para isso, é necessário refletir questões atinentes à filosofia da história, em especial através das contribuições do historiador britânico Michael Oakeshott sobre passado histórico, eventos históricos e o conceito de mudança. Ao utilizar o método hipotético-dedutivo, se pretende apresentar hipóteses gerais baseadas em uma atitude retórica e oakeshottiana e confrontar com dados documentais extraídos da Plataforma "Sesmarias do Império Luso-Brasileiro", buscando falsear a hipótese geral da pesquisa. Ao fim, as primeiras conclusões desta pesquisa possibilitarão uma reformulação das hipóteses gerais (no caso de terem sido falseadas diante dos dados históricos) ou uma contribuição teórica à discussão sobre a história da prática jurídica e das ideias jurídicas no Brasil Colonial.
\end{abstract}

Palavras-chave: Brasil colonial; Função social da propriedade; História das ideias jurídicas.

\begin{abstract}
This research aims to verify the hypothesis of previous state requirements about the fulfillment of some type of social function of property during the early stages of Colonial Brazil. For this, it is necessary to reflect issues pertaining to the philosophy of history, especially through the contributions of the British historian Michael Oakeshott on historical past, historical events and the concept of change. Using the hypothetical-deductive method, it is intended to present general hypotheses based on a rhetorical and Oakeshottiana model and to confront with documentary data extracted from the Platform "Sesmarias do Império Luso-Brasileiro", seeking to falsify the general hypothesis. In the end, the first conclusions of this research will make it possible to reformulate the general hypothesis (if they were falsified by historical data) or a theoretical contribution to the discussion about the history of legal practice and legal ideas in Colonial Brazil.
\end{abstract}

Keywords: Colonial Brazil; story of legal ideas; social function of property.

\footnotetext{
* Bacharel, Mestre e Doutor em Direito pela Universidade Federal de Pernambuco (UFPE). Professor de Direito Civil e de Direito Empresarial na Universidade de Pernambuco(UPE) e Professor Permanente do Programa de Pós-Graduação em Direito da UFPE. Advogado. E-mail: venceslau @ metropolitana.edu.br. ** Mestrando em Direito na Universidade Federal de Pernambuco (UFPE). Bacharel em Direito pela Universidade Federal do Rio Grande do Norte (UFRN). Advogado. E-mail: pedro29@ufrn.edu.br.
} 
Compreensão da função social da propriedade no Brasil colonial: repensando a evolução das ideias jurídicas a partir de Oakeshott

\section{INTRODUÇÃO}

Compreender o passado tem sido um dos desafios mais complexos da humanidade, gerando as mais diversas teorias sobre a função e importância do estudo científico da história ou mesmo sobre qual método deve ser utilizado.

Inicialmente, cabe esclarecer alguns pontos preliminares sobre este estudo antes de iniciar qualquer análise: afinal, todo historiador ou qualquer indivíduo que pretenda "ler a história" parte de algumas pré-compreensões, o que torna difícil o exame de contextos históricos e culturais diferentes do meio em que está inserido.

Nesse sentido, para que seja possível interpretar a função social da propriedade (para fins de delimitação, será examinada apenas o aspecto da concessão e uso das terras) na época inicial do Brasil Colonial (objeto desta pesquisa), é preciso identificar quais os sentidos de eventos históricos que estão sendo abordados neste trabalho. Para isso, a abordagem do historiador britânico Michael Oakeshott será de grande relevância ao examinar não apenas o significado do que vem a ser o passado, mas também quando tematiza sobre as mudanças sociais (aplicáveis às mudanças do ordenamento jurídico) e ainda nega a existência de uma relação de causalidade entre eventos históricos, apesar de reconhecer que estes possam ter algum tipo de relação. Assim, o tópico 2 deste ensaio elucida os principais pontos do pensamento oakeshottiano sobre investigação histórica, retomando um diálogo (extremamente pertinente à presente análise) sobre a filosofia da história do direito brasileiro que, muitas vezes, tem sido negligenciado.

Em seguida, tal abordagem oakeshottiana sobre eventos passados levará a investigação a um reencontro com as perspectivas retóricas no estudo da história. Dessa forma, o tópico 3 assume significativa importância para a formulação das hipóteses gerais sobre a função social da propriedade imóvel na época e contexto do Brasil Colonial, principalmente com base na atitude retórica desenvolvida por João Maurício Adeodato.

No tópico 4, são apresentadas as análises acerca dos dados obtidos na Plataforma Sesmarias do Império luso-brasileiro.

Por fim, tendo sido realizadas as discussões sobre o pensamento de Michael Oakeshott (tópico 2), as perspectivas retóricas para compreensão da função social no 
Brasil Colonial (tópico 3) e ainda o diálogo entre as hipóteses gerais da pesquisa com os dados obtidos a partir de informações oficiais (tópico 4), será exposta a contribuição científica desta pesquisa para uma possível teoria da evolução histórica das ideias jurídicas, sendo apresentadas novas problemáticas para futuras pesquisas na área da história do direito brasileiro.

\section{MICHAEL OAKESHOTT E A QUESTÃO DOS EVENTOS HISTÓRICOS}

Inicialmente, é importante ressaltar que Michael Oakeshott não teve formação estritamente jurídica ou mesmo não há registros de que tenha feito pesquisas sobre a propriedade privada no Brasil. Entretanto, Oakeshott é um cientista político e filósofo da história que ensinou em algumas das principais universidades do Reino Unido no século passado e possui diversos trabalhos acadêmicos relevantes.

Embora tenha se tornado mais conhecido no Brasil pelos seus trabalhos no campo da ciência política, Oakeshott também desenvolveu ideias sobre a investigação histórica que guardam pertinente ligação com a história das ideias jurídicas.

Para compreender o pensamento de Oakeshott e sua contribuição ao estudo da história (seja a história das ideias políticas, das ideias jurídicas, dos costumes sociais ou qualquer outra), cabe registrar a primeira advertência: o entendimento da história é “[...] exclusivamente preocupado com o passado" (OAKESHOTT, 2003, p. 76). Ou seja, não se busca compreender o passado para entender o presente ou para prever o futuro (embora possam existir correntes que aleguem o contrário).

Assim, surge a diferenciação entre "entendimento histórico" e "entendimento prático". Enquanto o primeiro teria essa preocupação exclusiva com o passado, o entendimento prático pode ou não estar preocupado com o passado. Segundo Oakeshott (2003, p. 76), caso o entendimento sobre algo não tenha nenhuma preocupação com o passado, este seria um "entendimento estético" enquanto que o “entendimento prático" pode acumular preocupações com o passado, presente e futuro.

Para elucidar essa distinção entre entendimento prático e entendimento histórico, é possível dizer que existe também um "passado prático" e um "passado histórico", sendo que o primeiro é uma espécie de passado contínuo, ou seja, algo que iniciou no passado e permanece até hoje. De modo divergente, o passado histórico é um tempo pretérito que se encerrou e não foi mantido. Nesse sentido, assinala que 
Compreensão da função social da propriedade no Brasil colonial: repensando a evolução das ideias jurídicas a partir de Oakeshott

Se atribuímos algum mérito superior ao que sobreviveu pelo simples fato de ter sobrevivido, não lhe estamos atribuindo uma importante posição no passado, mas apenas considerando a atual utilidade por conta de sua durabilidade (OAKESHOTT, 2003, p. 89).

Ora, tal ideia apresenta fortes repercussões para o campo do direito. Primeiro, porque é possível concluir que, nos termos oakeshottianos, "passado vivo" não é passado histórico, mas sim algo presente influenciado pela tradição e mantido pela prática. Porém, em seguida, é preciso afirmar que isso não significa que institutos jurídicos do passado prático se mantiveram da mesma forma ao longo do tempo, mas há uma advertência muita clara para evitar anacronismos: não se devem buscar, no passado histórico, os mesmos institutos que existem hoje (embora possam receber o mesmo nome ou terem grandes semelhanças).

Parece haver, portanto, uma clara distinção entre pesquisa histórica e a pesquisa prática sobre ideias e institutos jurídicos. Quando se trata de pesquisa histórica, o que se busca é compreender os conceitos, metáforas e opiniões que sejam exclusivos do passado e que não foram mantidos. Por outro lado, a "pesquisa prática" não está contida no entendimento histórico, pois também se preocupa com o tempo presente: pode questionar o motivo de ter sobrevivido ou ainda diferenças do seu uso em variados contextos históricos e culturais até chegar ao tempo presente.

Embora seja muito comum que os institutos jurídicos sejam vistos como construções históricas (basta observar qualquer manual jurídico para se deparar com evoluções históricas), muitos desses institutos sofreram modificações tão fortes que pouco tem a ver com sua origem. Mas o que vem a ser a mudança? As mudanças das ideias jurídicas ocasionam a manutenção (passado prático) ou a construção de novas formas de pensar (tornando as antigas ideias objetos da pesquisa histórica)?

Segundo Oakeshott (2003, p. 164), “[...] a mudança é uma ideia paradoxal”, pois reuniria tanto a noção de alteração (se não há alteração, só houve permanência e inexiste mudança) como a noção de permanência (se não há permanência, algo deixou de existir e surgiu algo completamente novo): quando algo muda, este se altera em alguma medida, mas existe algo nele que permanece.

Como se vê, não é um assunto simples e é preciso observar caso a caso. Entretanto, tal distinção passa, aparentemente, despercebida na ciência jurídica atual. $\mathrm{Na}$ tentativa de lidar com este desafio e continuar no exame desta pesquisa, é mister explanar as subdivisões do passado: os eventos históricos. 
Acerca do conceito de eventos, Michael Oakeshott (2003, p. 123) afirma que evento histórico é o "[...] subproduto do passado composto de eventos antecedentes que não possuem caráter exclusivo, resultados predeterminados e potencialidades inerentes". Ora, eventos são antecedidos ou sucedidos por outros eventos, mas isso não significa dizer que exista uma causalidade histórica (OAKESHOTT, 2003, p. 149). Assim, é claro que os eventos possam ter algum tipo de relação (essa relação seria sempre contingente, embora os eventos em si não apresentem contingência) e se influenciem, mas Oakeshott nega que o passado antecedente venha a ser uma “incubadora” de eventos históricos subsequentes.

Sendo assim, o passado histórico poderia ser visto como "conjunto de passagens de eventos relacionados de várias dimensões, durabilidades e constituições" que fornece resposta a uma questão histórica e, assim, o passado seria constituído não em função de uma imobilidade situacional, mas sim “[...] em termos de tempo e mudança" (OAKESHOTT, 2003, p. 120).

Retornando à aplicação dessas ideias no campo jurídico, é possível pensar que a diferença entre passado histórico e passado prático é que a sucessão de eventos similares foi ou não interrompida. No passado histórico, por conta de fatores de ordem cultural, social ou econômica, os eventos que o sucederam ganharam contornos que os diferenciam bastante de seus antecedentes. De outro lado, a concepção de passado prático nos indica que eventos que sucederam esse tipo passado permanecem se repetindo (embora não exatamente iguais), podendo haver algum tipo de mudança na atuação desses eventos, mas ainda assim compartilhando algum tipo significativo de identidade.

Para ilustrar, é possível arguir que o instituto do casamento civil no Brasil permanece o mesmo, apesar das adaptações feitas pelo Poder Judiciário (o julgamento do STF que garantiu o casamento civil entre pessoas do mesmo sexo é, nestes termos, um evento histórico que manteve o instituto de direito civil com mudanças). Por outro lado, seria um grave anacronismo histórico sugerir que o fato de haver previsão expressa na Constituição de 1824 sobre um “direito aos socorros públicos” levaria à ideia de que a atual concepção de direitos sociais já estava presente nos primórdios do constitucionalismo brasileiro.

Mas e o caso da função social das terras brasileiras? Se, diante dos esclarecimentos feitos até aqui, a investigação histórica pode ser vista não apenas como 
Compreensão da função social da propriedade no Brasil colonial: repensando a evolução das ideias jurídicas a partir de Oakeshott

“[...] prestar contas de uma situação já entendida”, é preciso “[...] entender uma situação talvez anatomizada, mas ainda não entendida, por meio dos eventos antecedentes aos quais ela é significativamente relacionada" (OAKESHOTT, 2003, p. 122).

Portanto, para compreender os eventos históricos possivelmente relacionados com a ideia de função social da propriedade imóvel, a pesquisa passa a formular hipóteses de uma concepção retórica dos eventos relacionados à função social da propriedade (tópico seguinte) e sua confrontação com os dados obtidos a partir de fontes oficiais (tópico 4).

\section{HISTÓRIA DA FUNÇÃO SOCIAL DA PROPRIEDADE ATRAVÉS DE UMA PERSPECTIVA RETÓRICA}

Segundo João Maurício Adeodato (2010, p. 133), o mundo dos eventos (históricos) é sempre irracional, pois a razão humana trabalha sempre com conceitos gerais enquanto que os eventos são únicos e individuais. Ora, os indivíduos fazem leituras diferentes sobre os eventos (ou os relatos linguísticos sobre eles) e o que consideramos como "verdade" na história é apenas um acordo linguístico provisório que pode ser revisto a qualquer momento.

Seguindo essa ideia, a tolerância significa que outras leituras divergentes sobre os eventos históricos devem ser aceitas como válidas e aptas para o debate (e disputa) de narrativas. Assim, temos uma "ética da inclusão" baseada na defesa da subjetividade humana e crescente pluralidade em uma sociedade cada vez mais complexa: a "história do direito" passa a funcionar como disciplina que deve garantir um "espaço público" para divergências de leituras, argumentos e opiniões sobre os eventos históricos.

Em certo aspecto, a história pode ser vista como "[...] uma imagem presente de uma coisa ausente" (RICOEUR, 2007, p. 294). Tal assertiva permite uma interpretação retórica da história tal como proposta por Adeodato (2010,), ou seja, os eventos históricos seriam em si inacessíveis, porém seus relatos provisórios podem ser conhecidos, alterados e reinterpretados no presente.

Entretanto, Ricoeur (2007, p. 294) deixa um alerta: “[...] as coisas passadas são abolidas, mas ninguém pode fazer com que não tenham sido". Ora, mesmo que acordos linguísticos intersubjetivos venham a negar que algo tenha de fato ocorrido 
(como é possível em uma perspectiva retórica), haverá sempre alguma objetividade a ser revelada ou descoberta em algum momento (talvez nunca seja, mas sempre há a possibilidade, pois é impossível desfazer o que foi feito mesmo que se reduza a vida à linguagem).

Portanto, a presente pesquisa não se utiliza de uma perspectiva "retórica realista radical", mas apenas se inspira nessa forma de pensar para afastar três erros comuns: a importância da mudança enaltecida pelo historicismo (POPPER, 1959, p. 27), a visão equivocada de que a realidade é um encadeamento causal de eventos em que o passado cria o presente (etiologia) e o presente cria o futuro (escatologia), além do senso comum de que o futuro sempre será melhor que o hoje quando, em verdade, o mundo dos eventos é um mundo irracional (ADEODATO, 2010, p. 133).

Para compreender a propriedade de terras nos primórdios do Brasil, é interessante o relato de Capistrano de Abreu (1960, p. 261) sobre as duas fases de povoamento no Ceará, uma história marcada por tragédias, lutas e sofrimento no sertão nordestino brasileiro: na primeira fase, os "homens ricos de outras capitanias" que requereram e obtiveram sesmarias decidiam mandar vaqueiros com "sementes de gado". Durante esta fase, os fazendeiros dificilmente chegariam a visitar suas propriedades com frequência. Mas, posteriormente, surgiu uma nova fase com o estabelecimento de fazendeiros em suas propriedades do interior sertanejo, época em que será acelerado o processo de povoamento no interior.

Ainda que se afirme que a pesquisa histórica consiste em "[...] reunir e juntar todas as interpretações do passado e do presente sobre determinado tema histórico" (REIS, 2007, p. 175), não se pode conceber o historiador como mero compilador de relatos. Assim, embora seja pertinente este relato de Capistrano de Abreu sobre um dos momentos do Brasil Colonial, é preciso buscar mais dados e evitar conclusões precipitadas. Portanto, o que se busca são conclusões provisórias, intermediárias para futuras reflexões.

Em uma investigação como essa, cabe também observar rapidamente os primórdios da propriedade em Portugal para compreender o uso da terra. Nesse sentido, é possível perceber a existência de relatos no sentido de que a origem da nobreza estaria relacionada inicialmente às obras que distinguem os homens, mas pelo menos após a Reconquista, os "filhos dalgo" ganharam força e conseguiram posições privilegiadas com base em sua ascendência e houve ainda a promoção direta de servidores da Casa 
Compreensão da função social da propriedade no Brasil colonial: repensando a evolução das ideias jurídicas a partir de Oakeshott

Real que não tinham "base econômica brilhante" (CASTRO, 1964, p. 27-28). Certamente, esse cenário influenciou na concepção de divisão de terras portuguesas e poderia também refletir na concessão de terras no Brasil.

Segundo Armando Castro (1964, p. 138-139), não se pode falar no termo "propriedade" durante os séculos XII a XV em Portugal porque este conceito "[...] se reformulou totalmente no capitalismo e não pode ser confundido com as relações econômicas medievais". Assim, este posicionamento também repercute na presente pesquisa: para evitar anacronismos históricos, também não se poderia falar em propriedade (muito menos em sua "função social") no Brasil Colonial ou mesmo no Brasil Imperial.

Assim, Castro (1964, p. 140-141) sugere a adoção do termo "alódio" que significa "livre de encargos". Porém, não significa dizer que alódio seria livre de todo e qualquer encargo, mas sim a ideia de que as explorações agrícolas e agropecuárias não seriam submetidas a pagamentos ou prestações. Para fins dessa concepção alodial, Castro evita a presença de elementos como o "grau de disponibilidade do solo pelo camponês" e a transmissão da terra aos descendentes na caracterização do alódio.

Em sua pesquisa, porém, Castro (1964, p. 154) encontra diversos tipos de prestações que afastariam a possibilidade da existência do alódio naquela época, tais como a fossadeira (geralmente, alguns metros de linho entregues anualmente ao Rei, ao mosteiro ou a um fidalgo), primícias, mortuárias e "votos de Santiago" (estes no Norte português). Embora não fossem encargos necessariamente fiscais, poderiam ser vistos como encargos econômicos que comprometeriam a ideia de uma propriedade livre ou o alódio nos termos por ele definidos.

Apesar disso, é encontrada certa proximidade com as terras alodiais que seriam exceções. Tais terras exerceriam "função social" e estariam geralmente relacionadas a motivos assistenciais: é o caso da Lezíria da Valada que consistia em distribuição anual de terras para pobres, leprosos e deficientes e a Coroa Portuguesa não exigia rendas dessas terras (CASTRO, 1964, p. 158-159), além de ser comum a dispensa dos encargos econômicos quando se tratava de “[...] viúvas, velhos e órfãos" (CASTRO, 1964, p.161).

Reunindo, portanto, estes primeiros relatos sobre a propriedade em Portugal e o povoamento no nordeste brasileiro, esta pesquisa chega à ideia de que o procedimento de concessão de terras pelo Poder Público envolvia, por si só, uma lógica 
que poderia ser de "prêmio" por atos heroicos ou de grande relevância para a Coroa Portuguesa, ou que descendiam de "boas famílias", ou ainda exercia algum tipo de funcionalidade no desenvolvimento da colônia (que também envolve função social).

\section{ANÁliSE DE DADOS DOCUMENTAIS E LANÇAMENTO DE NOVAS HIPÓTESES}

Há alguns anos, professores dos Departamentos de História da Universidade Federal do Rio Grande do Norte (UFRN), da Universidade Federal do Pará (UFPA) e da Universidade de São Paulo (USP) desenvolveram um banco de dados com informações acerca de milhares de cartas de sesmarias concedidas tanto por governadores como capitães-mores, além de alguns com confirmação régia. Esse banco de dados resultou na Plataforma SILB (Sesmarias do Império Luso-Brasileiro) e representa atualmente importante fonte de dados sobre as cartas de sesmarias, inclusive porque grande parte contém a justificação do pedido do requerente e a determinação de diversas obrigações pelo Poder Público, principalmente obrigações de cultivo, criação de animais, demarcação de terra e construções.

Para fins da presente pesquisa, a Plataforma SILB foi fundamental para a obtenção de dados e verificação das hipóteses levantadas nos tópicos anteriores, constituindo importante passo metodológico.

Em um primeiro passo, diante da impossibilidade de verificar todas as cartas de sesmaria para fins do presente trabalho, foram adotadas algumas delimitações para facilitação da análise dos dados: demarcação temporal e demarcação geográfica.

Considerando que o período de colonização do Brasil é bastante extenso, os primeiros dados obtidos nessa pesquisa resultaram da demarcação temporal compreendida entre $1^{\circ}$ de janeiro de 1532 e 22 de abril de 1650 (150 anos da chegada de Pedro Álvares Cabral no Brasil).

Apesar dessa delimitação, o sistema de busca da plataforma apresentou um total de 183 registros de sesmarias, sendo necessário adotar um segundo critério de delimitação dos dados: a demarcação geográfica.

Assim, a presente pesquisa efetuou a busca pelas sesmarias compreendidas nessas datas apenas no que se refere a Pernambuco e Paraíba, gerando um total de 25 documentos a serem analisados. 
Compreensão da função social da propriedade no Brasil colonial: repensando a evolução das ideias jurídicas a partir de Oakeshott

Dentre os 25 registros analisados, apenas três estão identificados como Pernambuco: uma concessão a Gaspar Dias em Recife em 1590, uma concessão a Pedro Cunha de Andrade em "Tapicurá - Mata do Brasil” em 1612 e outra concessão a um João Batista em "Mucuripe - Freguesia São Lourenço" em 1577.

$\mathrm{Na}$ justificativa de Gaspar Dias, consta que ele teria alegado residir nas terras solicitadas há bastante tempo e que havia construído casas nela, tendo seu pedido sido deferido pelo capitão Filipe Cavalcanti em nome do governador Jorge Coelho. Quanto a Pedro Cunha, este alegou ser dono do engenho "Trapiche" que produzia bastante açúcar, pagava uma taxa de $3 \%$ sobre os lucros do engenho e precisava de pastos para os bois que poderiam ser utilizados no funcionamento do engenho, tendo seu pedido sido acatado por Duarte Coelho. No terceiro documento, de João Batista, consta o parcial deferimento do governador Jerônimo Albuquerque pelas justificativas de que o requerente não possuía terras, pretendia cultivar nas terras e era dono de escravos. Ademais, João Batista também alegou morar na capitania há oito anos e que pretendia povoar e viver na terra.

Em seguida, há outros sete registros que encerram a primeira dezena de resultados: uma concessão próxima ao "rio Gramame” para Luis Gomes Serrilho em 1598, uma concessão às margens do "rio Guajau" para João Marques em 1607, outra concessão às margens do "rio Guajau" e divisa entre Rio Grande e Paraíba para Agostinho Pereira em 1607, duas concessões de terra às margens do "rio Camaratuba" para Domingos Sirgno em 1604, uma concessão no "rio Mamanguape" para Antonio de Valcacer Morais em 1624 e uma concessão às margens do "rio Una" para Duarte Gomes da Silveira em 1621.

No que diz respeito às justificativas destes últimos documentos, se destaca a justificativa de Luis Gomes: alegou que servia à Coroa Portuguesa há 20 anos, participando na jornada de El-Rei D. Sebastião na África, na expedição com Manuel Mascarenhas Homem em navegação que saiu da Índia para o Brasil trazendo "aumentos reais", serviu na capitania de Pernambuco e de lá se estabeleceu na cidade de Filipeia de Nossa Senhora das Neves, socorrendo a cidade por duas vezes e se oferecendo como "vigia da capitania", dentre outros feitos.

Entretanto, inexistem registros das justificativas dos requerimentos de João Marques, Agostinho Pereira e as duas de Domingos Sirgno. 
Quanto às justificativas de Antonio de Valcacer e Duarte Gomes, o primeiro alegou que já residia nas terras, que lutou contra os índios e que pretendia cultivar e criar gado, tendo seu pedido sido deferido pelo então capitão-mor Afonso de França. O segundo alegou apenas que possuía poucas terras e que pretendia fazer engenho de açúcar nos terrenos vizinhos aos seus, tendo sido deferido seu pedido pelo capitão-mor João de Brito Correia.

Prosseguindo com a pesquisa, foram encontradas concessões de terra para Pedro Cadena em 1621 por possuir engenhos e necessitar de madeira e lenha e com a justificativa de ampliar seu engenho (rio Paraíba), Manuel de Lima em 1621 por participar das "guerras de conquista” entre 1593 e 1621 (várzeas de Pacatuba), Rafael Carvalho e Francisco Pardo em 1619 por também terem participado das "guerras de conquista" e por pretender instalar fábricas e já possuir escravos (Serra da Copaoba, na ribeira do Curimatau), outra exclusiva para Rafael Carvalho pela contribuição para expulsão de piratas, pela participação nas guerras da Capitania e com o objetivo de plantar nas terras (rio Mamanguape) e para Antonio de Sampaio em 1615 com a justificativa que já possuía gado e pretendia fazer curral (rio Camaratuba).

Na sequência, os últimos dez arquivos encontrados são as concessões feitas para Pedro Hara Ravasco em 1615 (rio Camaratuba), Afonso Neto em 1615 (rio Mamanguape), Francisco Gomes de Oliveira em 1615 (rio Camaratuba), para a Aldeia Indígena da Jacoca em 1614 (Barra do Gramame, entre o rio Jacoca e o rio Tibiri), Antônio Fernandes Brandão em 1613 (rio Gargau), duas concessões para a Ordem de São Bento (uma em 1599 e outra em 1595 na atual cidade de João Pessoa), outra para Gaspar Gonçalves em 1589 (Rua Nova de Filipeia de Nossa Senhora das Neves), Francisco Gonçalves Serralheiro em 1587 (rio Jaguaribe) e para um João Afonso em 1586 (rio Paraíba).

No caso de Pedro Ravasco, a justificativa era baseada em seus serviços à Coroa Portuguesa e pela pretensão de cultivar nas novas terras. Por outro lado, as terras de Afonso Neto foram requeridas com base em sua participação nas guerras da conquista da Capitania. Enquanto Francisco Gomes alegou que já ocupava a terra requerida, não possuía terras, serviu à Coroa, possuía gado e pretendia plantar roça, Antônio Brandão alegou ter participado da guerra contra os holandeses e disse que pretendia fazer engenho de açúcar. 
Compreensão da função social da propriedade no Brasil colonial: repensando a evolução das ideias jurídicas a partir de Oakeshott

Por sua vez, a Aldeia da Jacoca apresentou três justificativas para requerer as terras: era uma comunidade indígena, lutou ao lado dos "brancos" para o povoamento e queriam a carta de sesmaria para "se igualar aos brancos", além de que tais terras não serviriam para engenho.

Ademais, a Ordem de São Bento requereu duas terras em Filipeia de Nossa Senhora das Neves (atual João Pessoa): a primeira em 1595 e a segunda em 1599, deferidas pelo então governador Feliciano Coelho de Carvalho. Na primeira, a justificativa feita pelo padre frei Damião da Fonseca girava em torno de ser um "grande serviço a Deus e ao povo cristão" e que eram terras devolutas, havendo a necessidade de edificar um mosteiro, solicitando pagar apenas o dízimo. Na segunda vez, porém, a justificativa feita pelo padre frade Anastacio solicitava terras com a pretensão de vendêlas para poder construir o mosteiro na cidade, além do pedido para sustento de três ou quatro religiosos da Ordem e do pedido por material de construção (telhas e madeiras) que sobrou da construção do mosteiro dos franciscanos na mesma cidade. Segundo o padre Anastacio, os "franciscanos abandonaram o seu serviço a Sua Majestade e a doutrina dos índios”. Neste segundo caso, houve não apenas a concessão das terras como também de 100 mil réis para o sustento dos religiosos e o deferimento do material de construção.

Por fim, Gaspar Gonçalves justificou sua solicitação por ter participado das guerras da conquista da Capitania e servir à Coroa, além de se considerar o primeiro povoador da área e pretender construir uma casa. Por sua vez, Francisco Gonçalves justificou apenas pelo interesse de construir benfeitoria, mas seu deferimento foi condicionado pelas exigências de demarcação da terra, efetivar a posse e com a obrigação de "adentrar os sertões". Já sobre João Afonso, este apresentou como justificativas a necessidade de madeira e lenha, possuir cabedal e escravos, ter as pretensões de cultivar na terra, fazer benfeitoria e exercer posse efetiva e pessoal, além de ter alegado ter participado da conquista da Capitania com sua fazenda e ter servido à Coroa.

Portanto, o que se pode extrair dessas primeiras informações é que no período e regiões pesquisadas, a causa mais citada nos requerimentos pela terra era relacionada aos seus serviços à Coroa Portuguesa e à nação, com destaque para lutas contra índios, guerras da conquista da capitania, dentre outras, sendo citados em $44 \%$ dos documentos. 
Em seguida, aparecem como principais justificativas a pretensão de cultivo nas terras $(24 \%)$ ou construção de benfeitorias, mosteiros ou fábricas (24\%). Outras causas como criação de gado (16\%) e construção ou ampliação de engenhos (16\%) também são frequentes.

Apesar de existirem outras causas, é interessante notar a "função social" da concessão de terras para criação de mosteiros e também para a Aldeia indígena de Jacoca que alegou, inclusive, a possibilidade de "igualdade com os brancos" se conseguissem a carta de sesmaria.

De fato, o que chamamos aqui de "função social" nada tem a ver com a noção dessa expressão nos dias atuais quando funciona muito mais como limitações ao gozo dos direitos de propriedade e não tanto como mecanismo e critérios de distribuição da terra.

\section{PANORAMA EVOLUTIVO E A MISSÃO DO HISTORIADOR NO CAMPO DAS IDEIAS JURÍDICAS}

Considerando, portanto, que a "verdade histórica" é como um processo infinito que acumula verdades parciais e contextuais que os indivíduos estabeleceram nas suas fases de desenvolvimento (SCHAFF, 1995, p. 97), então como pensar sobre a funcionalidade do historiador no campo jurídico?

Em primeiro lugar, cabe pontuar que os historiadores - pela própria condição humana - são limitados e estão imersos a valores individuais e sociais e isso reflete na construção dos relatos sobre a história. Conforme ensina Marrou (1978, p. 54), a história e o historiador são inseparáveis e o “[...] valor da história está estritamente subordinado ao gênio do historiador".

Seguindo esta lógica, muitos poderiam alegar a necessidade de uma abordagem cética que não se preocupa com a possível existência “da verdade". No entanto, a esse respeito, é válido alertar que

\footnotetext{
Quando os homens relatam a história, têm a intenção de transmitir a verdade objetiva e estão convencidos de terem realmente encontrado a verdade, mas o conhecimento histórico é deformado para além da consciência do historiador, apesar de suas intenções e aspirações. (SCHAFF, 1995, p. 12)
}

Sendo assim, seria natural a busca pela verdade - nenhum historiador eticamente responsável buscaria ludibriar o público - e o "antinatural” seria negar essa R. Fac. Dir. UFG, v. 42, n. 1, p.32-47, jan/abr. 2018 
Compreensão da função social da propriedade no Brasil colonial: repensando a evolução das ideias jurídicas a partir de Oakeshott

busca. Porém, o grande problema é o reconhecimento da possibilidade de estar errado (a deformação do conhecimento histórico para além da consciência do historiador) e, portanto, seria um grave erro a imposição dessas "verdades". Reconhecer, portanto, "as fraquezas da própria razão" seria a pior forma de irracionalismo (ZAIDAN FILHO, 1989, p. 17) e precisa ser afastado da investigação histórica.

Para responder as críticas quanto à busca da verdade pelo historiador, Schaff (1995, p. 198) aponta que, para evitar o “abuso da verdade", é preciso reconhecer verdades parciais e adotar a modéstia e humildade científicas como bases para uma sociologia do conhecimento. Afinal, não é preciso escolher "[...] entre um dogmatismo cego ou um criticismo desalentado" (MARROU, 1978, p. 194).

É que, tal como afirma Michel Zaidan Filho (1989, p. 73), o historiador precisa ser crítico: deve "estranhar" seu objeto de estudo e ser crítico ao cotidiano de sua e de outras sociedades.

Dessa forma, as hipóteses iniciais do trabalho apenas parcialmente foram confirmadas. Independente disso, a visão da evolução das ideias jurídicas precisa ser analisada com cautela tanto quando diz respeito a uma investigação sobre o "passado histórico" como quando se trata de "passado prático", não impondo "verdades" ou tratando as conclusões como pontos de chegada, mas sim como novos pontos de partida para novas pesquisas e reflexões.

Resta claro que, em uma visão retórica e oakeshottiana sobre os eventos históricos no campo jurídico, é preciso investigar o passado sem pretensões de trazer argumentos historicistas para o presente (enquanto historiador do direito).

$\mathrm{Na}$ breve caminhada realizada aqui acerca da função social da propriedade nos primeiros anos do Brasil Colonial, se percebe uma denotação bastante diferente na concessão de terras pela Coroa Portuguesa ou pelos seus legitimados: a existência de apresentação prévia de justificativas no requerimento pela posse ou propriedade pode sim ser vista como uma forma compreendida na época de exigência de uma "função social", porém sem jamais conter a ideia atual. Ao historiador, portanto, cabe buscar as verdades de determinado contexto histórico, mas ter a consciência de que novos fatos ou relatos sobre fatos podem aparecer e modificar a interpretação sobre o passado histórico.

\section{CONCLUSÃO}


A presente pesquisa analisou as justificativas prévias dos requerimentos de terras no Brasil Colonial na fase compreendida entre os primeiros 150 anos da chegada de Pedro Álvares Cabral ao Brasil e verificou que, pelo menos nas regiões de Pernambuco e Paraíba, o banco de dados fornecido por instituições públicas e utilizado aqui não possui nenhuma concessão de terras por critério nobiliárquico, ou seja, por mera ascendência. Pelo contrário, muito mais frequente é a ideia de importantes serviços prestados à Coroa Portuguesa seguida pelas intenções de cultivo nas terras, instalação ou ampliação de engenhos, benfeitorias e criações de animais.

Ao utilizar como marco teórico os estudos sobre história de Michael Oakeshott, foi facilmente estabelecido um diálogo com a proposta retórica sobre a história das ideias jurídicas defendida por João Maurício Adeodato que, embora se trate de marcos teóricos diferentes, convergem para um exame mais dinâmico e tolerante sobre a história.

Investigar a possível existência da função social da propriedade no Brasil Colonial, seguindo a lógica oakeshottiana, não é uma missão da investigação sobre o passado prático, mas sim sobre passado histórico do direito de propriedade em Portugal e no Brasil, pois o instituto não apenas sofreu mudanças, mas sim alterações influenciadas pelos sistemas econômicos, sociais e culturais que alteraram substancialmente seu sentido, sua razão de ser.

Observa-se, ao fim dessa pesquisa, que, apesar de os dados terem sido analisados apenas parcialmente em razão das estratégias de delimitação para fins da metodologia utilizada, as conclusões obtidas ao longo da pesquisa acerca dos exames individuais dos 25 documentos contribuem significativamente para melhor compreensão do direito naquela época.

Assim, os estudos jurídicos sobre o uso da terra no Brasil ganham novos contornos investigativos. Principalmente pela possibilidade de estudo documental e empírico que, tal como demonstrado nesta pesquisa, contribui para uma aproximação dos fatos passados que influenciaram nos desenhos institucionais do direito brasileiro, longe de uma pretensão de compreensão unívoca da realidade histórica.

\section{REFERÊNCIAS}

ADEODATO, João Maurício. História das ideias jurídicas no Brasil: metodologia de 
Compreensão da função social da propriedade no Brasil colonial: repensando a evolução das ideias jurídicas a partir de Oakeshott

estudo. In: SALDANHA, Nelson et al (org.). História do Direito e do pensamento jurídico em perspectiva. São Paulo: Atlas, 2012.

Uma teoria retórica da norma jurídica e do direito subjetivo. São Paulo: Noeses, 2010.

CAPISTRANO DE ABREU, J. Caminhos antigos e povoamento do Brasil. 2. ed. Rio de Janeiro: Livraria Briguiet, 1960.

CASTRO, Armando. A evolução econômica de Portugal dos séculos XII a XV. v. 2. Lisboa: Portugália Editora, 1964.

COSTA FILHO, Venceslau Tavares. O Direito entre a história e a razão: uma perspectiva sisífica. Palestra proferida. 2017.

MAIA, Alexandre da. Racionalidade e progresso nas teorias jurídicas: o problema do planejamento do futuro na história do direito pela legalidade e pelo conceito de direito subjetivo. In: BRANDÃO, Cláudio; CAVALCANTI, Francisco; ADEODATO, João Maurício. Princípio da legalidade: da dogmática jurídica à teoria do direito. Rio de Janeiro: Forense, 2009.

MARROU, Henri-Irénée. Sobre o conhecimento histórico. Trad. Roberto Cortes de Lacerda. Rio de Janeiro: Zahar Editores, 1978.

OAKESHOTT, Michael. Experience and its modes. Londres: Cambridge University Press, 1933.

. Sobre a história e outros ensaios. Trad. Renato Rezende. Rio de Janeiro: Topbooks, 2003.

POPPER, Karl. A miséria do historicismo. 2. ed. Trad. Octanny Mota e Leonidas Hegenberg. São Paulo: Editora Cultrix, 1993.

REIS, José Carlos. História e teoria: historicismo, modernidade, temporalidade e verdade. 3. ed. Rio de Janeiro: Editora FGV, 2007.

RICOEUR, Paul. A memória, a história, o esquecimento. Trad. Alain François. Campinas: Editora da Unicamp, 2007.

SCHAFF, Adam. História e verdade. Trad. Maria Paula Duarte. 6. ed. São Paulo: Martins Fontes, 1995.

ZAIDAN FILHO, Michel. A crise da razão histórica. Campinas: Papirus, 1989.

Artigo recebido em 22 de setembro de 2017 e aceito em 28 de fevereiro de 2018 